\title{
Aerodynamic Design of Heavy Vehicles Reporting Period January 15, 2004 through April 15, 2004
}

Rose McCallen, Kambiz Salari, Jason Ortega, Paul Castellucci, LLNL; Fred Browand, Mustapha Hammache, Tsun-Ya Hsu, Diego Arcas, University of Southern California; Anthony Leonard, Mike Rubel, Philippe Chatelain, California Institute of Technology; Larry DeChant, Bassil Hassan, J.L. Payne, Chris Roy, J.C. Brown, Sandia National Laboratories; Jim Ross, Bruce Storms, Rabindra Mehta, Steve Walker, J.T. Heineck, NASA Ames Research Center; David Pointer, Argonne National Laboratory

\section{February 24, 2003}




\section{DISCLAIMER}

This document was prepared as an account of work sponsored by an agency of the United States Government. Neither the United States Government nor the University of California nor any of their employees, makes any warranty, express or implied, or assumes any legal liability or responsibility for the accuracy, completeness, or usefulness of any information, apparatus, product, or process disclosed, or represents that its use would not infringe privately owned rights. Reference herein to any specific commercial product, process, or service by trade name, trademark, manufacturer, or otherwise, does not necessarily constitute or imply its endorsement, recommendation, or favoring by the United States Government or the University of California. The views and opinions of authors expressed herein do not necessarily state or reflect those of the United States Government or the University of California, and shall not be used for advertising or product endorsement purposes.

This work was performed under the auspices of the U. S. Department of Energy by the University of California, Lawrence Livermore National Laboratory under Contract No. W-7405-Eng-48.

This report has been reproduced directly from the best available copy.

Available to DOE and DOE contractors from the

Office of Scientific and Technical Information

P.O. Box 62, Oak Ridge, TN 37831

Prices available from (423) 576-8401

http: / / apollo.osti.gov/bridge/

Available to the public from the National Technical Information Service

U.S. Department of Commerce 5285 Port Royal Rd., Springfield, VA 22161 http:/ / www.ntis.gov/

OR

Lawrence Livermore National Laboratory Technical Information Department's Digital Library http:/ / www.llnl.gov/tid/Library.html 


\section{Quarterly Report}

Reporting Period: January 15, through April 15, 2004

Project Title: $\quad$ Aerodynamic Design of Heavy Vehicles

Investigators: $\quad$ Rose McCallen, Kambiz Salari, Jason Ortega, Paul Castellucci

Lawrence Livermore National Laboratory

Fred Browand, Mustapha Hammache, Tsun-Ya Hsu, Diego Arcas,

University of Southern California

Anthony Leonard, Philippe Chatelain, Mike Rubel

California Institute of Technology

Larry DeChant, Basil Hassan, J.L. Payne, Chris Roy, J.C. Brown

Sandia National Laboratories and collaborators from Auburn University

Jim Ross, Bruce Storms, Rabindra Mehta, Steve Walker, J.T. Heineck

NASA Ames Research Center

David Pointer

Argonne National Laboratory

\subsection{Activities and Accomplishments}

\subsection{Summaries}

Attached are summaries of the activities and accomplishments during this second-quarter reporting period for each of the consortium participants. The following are some highlights for this reporting period:

- Experiments and computations guide conceptual designs for reduction of drag due to tractortrailer gap flow (splitter plate), trailer underbody (wedges), and base drag (base-flap add-ons).

- Steady and unsteady RANS simulations for the GTS geometry are being finalized for development of clear modeling guidelines with RANS.

- Full geometry and tunnel simulations on the GCM geometry are underway.

- CRADA with PACCAR is supporting computational parametric study to determine predictive need to include wind tunnel geometry as limits of computational domain.

- Road and track test options are being investigated. All is ready for field testing of base-flaps at Crows Landing in California in collaboration with Partners in Advanced Transportation Highways (PATH). In addition, MAKA of Canada is providing the device and Wabash is providing a new trailer. 
- Apparatus to investigate tire splash and spray has been designed and is under construction. Michelin has offered tires with customized threads for this study.

- Vortex methods have improved techniques for the treatment of vorticity near surfaces and spinning geometries like rotating tires.

- Wind tunnel experiments on model rail cars demonstrate that empty coal cars exhibit substantial aerodynamic drag compared to full coal cars, indicating that significant fuel savings could be obtained by reducing the drag of empty coal cars.

- Papers are being prepared for an exclusive conference session on the Heavy Vehicle DOE Aerodynamic Drag Project at the $34^{\text {th }}$ AIAA Fluid Dynamics Conference in Portland, Oregon, June 28 - July 1, 2004.

\subsection{Publications for United Engineering Conference}

The papers have been reviewed, final edits submitted, and the package has been sent to the publisher. The published document should be shipped to all conference participants on or before July 31, 2004.

\subsection{Future Plans}

A DOE Heavy Vehicle Aero Drag Team Working Group meeting is planned for July 1, 2004 on the final day of the AIAA conference in Portland, Oregon. Industry is invited to participate. Consortium participants will provide a status report, discuss remaining activities for FY04, and review plans for FY05. 


\section{Lawrence Livermore National Laboratory}

Activities for this quarter include both a computational and an experimental effort. The focus of the computational effort has been to finalize the GTS computational simulations, the results of which will be published in the proceedings of an AIAA summer conference. The GTS experimental data obtained at NASA Ames 7'x10' wind tunnel have been extensively studied and utilized in validating our computational simulations. Leveraging LLNL's internal technology development efforts, the development and implementation of a new RANS/LES hybrid turbulence model is underway. Several test cases have been identified to validate the new model. Unsteady gap flow simulations representing the USC wind tunnel experiments with gap add-on devices are in progress to validate the force calculation for an overset grid. This is required to correctly ascertain the drag reduction benefits of the gap add-on device. A follow-on discovery experiment has been conducted at the NASA Ames smallscale 3 ' $x 4$ ' wind tunnel to provide additional insight into LLNL drag reduction concepts for underbody and base drag.

\section{Flow Simulations}

Steady and unsteady RANS flow simulations are being performed with OVERFLOW. Several turbulence models are used to investigate the overall flow structure around the vehicle, the wake flow structure, and aerodynamic forces as compared to the NASA Ames experimental observations. The GCM model is used to investigate computationally the two add-on devices that were identified in our discovery experiment to have good drag reduction capabilities. We are in the process of verifying the performance of these devices at low Reynolds number (wind-tunnel condition) and at high Reynolds numbers using computational simulations (Star-CD). The results of our modeling and simulations will be summarized in a paper to be presented at the 34th AIAA Fluid Dynamics Conference and Exhibit in July.

Work has begun on the following simulations of the GTS experiments in the NASA Ames 7'x10' wind tunnel:

$0^{\circ}$ yaw, $\mathrm{M}=0.28$, and $\mathrm{Re}=2.0 \times 10^{6}$ based on trailer width

Three turbulence models have been investigated, 1-equation model of Spalart-Allmaras, 2-equation models of Wilcox $k-\square$ and Menter SST. Two-grid resolutions of 9 and 17 million grid points are used for a grid convergence study.

$10^{\circ}$ yaw, $M=0.28$, and $\mathrm{Re}=2.0 \times 10^{6}$ based on trailer width

Three turbulence models have been investigated, 1-equation model of Spalart-Allmaras, 2-equation models of Wilcox $k-\square$ and Menter SST, with two grid resolutions similar to the above $0^{\circ}$ yaw case.

\section{Discovery Experiments}

The follow-on discovery experiments (second set of 2) were used to further study the effectiveness of two add-on devices that were highlighted in the previous discovery experiments. Axial force measurements were made on a 1/16th scale generic tractor-trailer model in the NASA Ames open-circuit wind tunnel. The base flaps and alternate forms of trailer skirt/underbody devices were studied for further optimization. Previous results on the straight base flaps (Fig. 1a) demonstrated that this concept is capable of substantially reducing the drag when the flaps are deployed at equal angular deflections. In the follow-on experiments, 
alternative configurations were investigated for additional optimization in which the top and side base flaps have different angular deflections. The curved base flaps (Fig. 1b) that were previously shown to perform equally well compared to straight base flaps were tested to understand if further drag reduction is possible. To circumvent the shortcomings of straight side skirts, which limit access to the trailer underside, three variations of a wedge trailer skirt/underbody device concept may provide the drag reduction benefits of straight side skirts, while allowing access to the trailer underside. The results obtained in the discovery experiments will be summarized in an AIAA paper to be presented at the 34th AIAA Fluid Dynamics Conference and Exhibit in July.

\section{Full-Scale Experiments}

An investigation of appropriate and economical test plans and sites for full-scale field testing has been challenging. Possibilities include the Transportation Research Center, Inc. in Ohio, the Crows Landing vacant air strip in California, and the option of teaming with the California Trucking Association for road testing. Communications and guidance from PACCAR Research Center have been very insightful. It is recognized that full-scale field testing on the road or at a track test facility of identified promising devices is critical for industry consideration and acceptance.

\section{Publication}

Results of Ground Transportation System (GTS) flow simulations to be presented at the 34th AIAA Fluid Dynamics Conference in July of 2004.

Results of Discovery experiments to be to be presented at the 34th AIAA Fluid Dynamics Conference in July of 2004.

Overview Paper to be presented at the 34 ${ }^{\text {th }}$ AIAA Fluid Dynamics Conference in July of 2004.

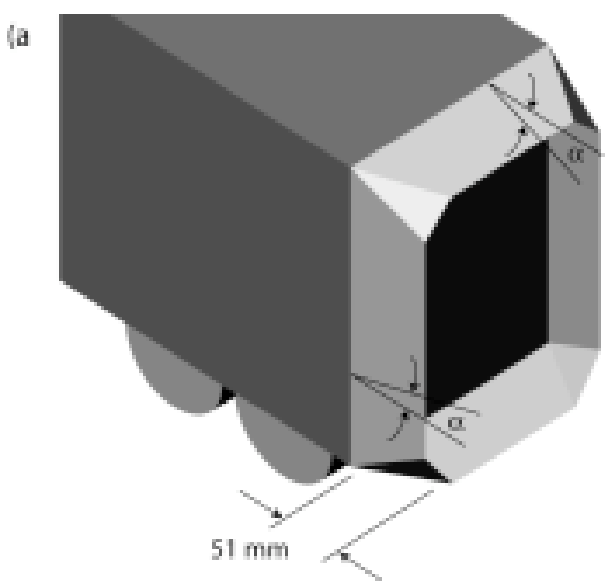

Figure 1. Base drag reduction devices: a) straight base flaps; b) curved base flaps. (b

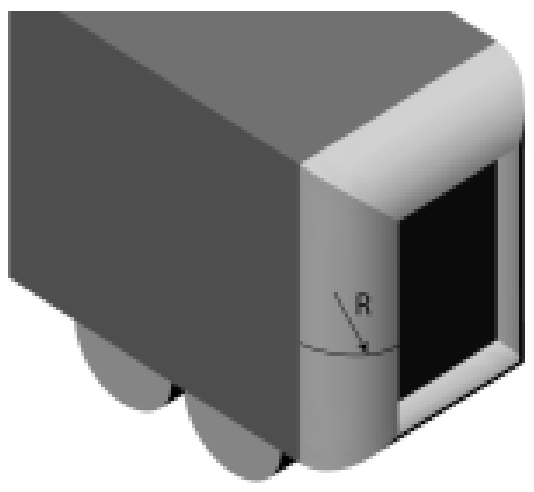




\section{Sandia National Laboratories}

Our efforts are focusing towards Unsteady Reynolds Averaged Navier Stokes (URANS) type simulations to provide computational support to the Heavy Vehicle Drag project. We believe that URANS may offer an optimal compromise between solution fidelity as compared to computational cost. The "traditional" URANS focus work will fall to SNL while collaborators from Auburn University (contracted by SNL) will focus more on the Detached Eddy Simulation (DES) based tasks. DES utilizes hybrid RANS/LES models. Auburn University collaborators are also responsible for organization of a special session focusing on vehicle aerodynamics at the $34^{\text {th }}$ AIAA Fluid Dynamics conference in Portland, Oregon, 06/28/04 through 07/01/04.

Preliminary studies have been focused on unsteady RANS/URANS truncated GTS work, setting up and running a simple, but smooth test problem (sphere in an unsteady flow); a classical case for understanding 3-D, separated wake flows. Leveraging internal research funds, SNL has been working on a surface mounted cube (under Sandia Engineering Sciences Research Foundation) and looking at low dissipation discretization schemes. These schemes are showing promise for reducing grid sizes for unsteady flows by an order of magnitude. We'll use both of these "simple" flows to help test and understand URANS strength and limitations and use that experience base for the GTS.

Also supporting our code; SACCARA, we are in the process of submitting an LDRD for a compressible "all Mach" flow capability. If we obtain a years scoping money, it should enhance our low Mach simulation capability and also help delineate strength and weaknesses of preconditioned state coupled methods versus pressure projection methods.

Finally, as a smaller but potentially useful effort, we are looking at some preliminary/conceptual design methods for drag on bluff bodies to be presented at AIAA Fluid Dynamics Conference in Portland. A draft of the paper is complete and is currently in technical review.

To date, FY04 funding from DOE for the Heavy Vehicle Aerodynamics Project has not yet arrived at Sandia. We have made use of carryover funds from FY03 and are currently operating in the "red". Once the funding is received, we can continue in a more focused manner that continues to build our experience and provide dedicated support to the range of heavy vehicle aerodynamics efforts. 


\section{California Institute of Technology}

Caltech's activities for the first quarter consisted of work on near-wall elements for the vortex particle code with an initial application to spinning geometries and of work on asynchronous timestepping.

\section{Spinning Geometries and Attached Vortex Elements}

During this quarter, we pursued our work on near-wall vorticity representation and the treatment of spinning geometries. Vorticity very close to the wall is now represented with attached elements. These elements consist in the same panels used for surface representation. They carry a smooth distribution of vorticity and interact viscously with the free elements. The velocity field and its gradient are computed by means of the Biot-Savart law with an additional surface term induced by vorticity inside spinning objects. This was successfully applied to the flow around an impulsively started spinning ellipsoid at Re $\square$ 100, Fig. 1.
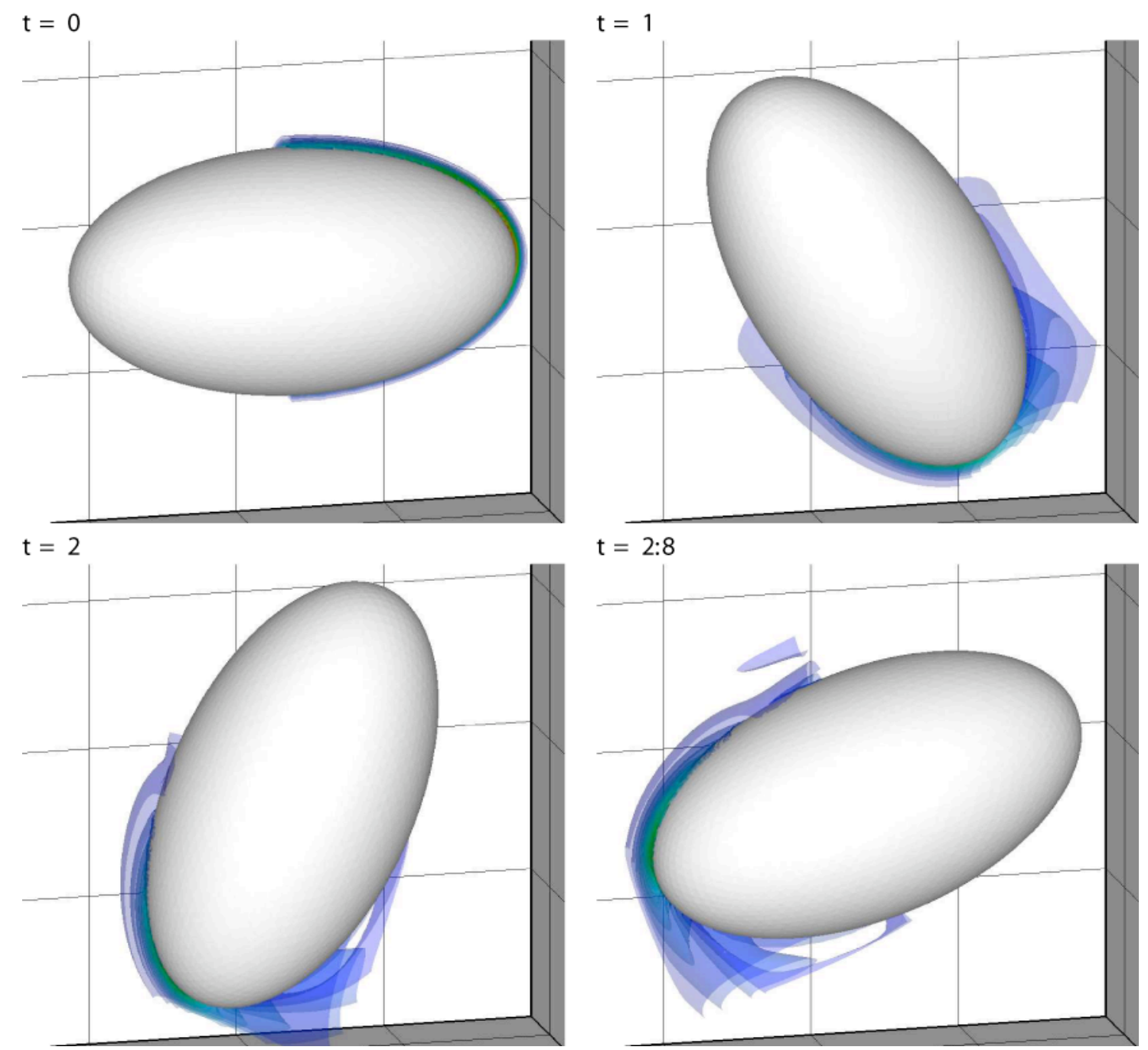

Figure 1: Impulsively started spinning ellipsoid at Re $\square$ 100, contours of vorticity magnitude: the sampled region covers one quarter of the ellipsoid and follows its rotation 


\section{Asynchronous Numeric Time Integration}

After a great deal of development, the asynchronous numeric time integrator has been applied to a 2-D vortex particle flow. The test flow, initially two Gaussian vortices of identical sign, each composed of 80 computational elements, is shown evolving in time (Figure 2). The integrator was able to adjust the initially-uniform particle timesteps as the flow evolved. A paper detailing the theory and operation of the timestepper, which will include discussions of order of accuracy, convergence, and stability, is now in preparation.
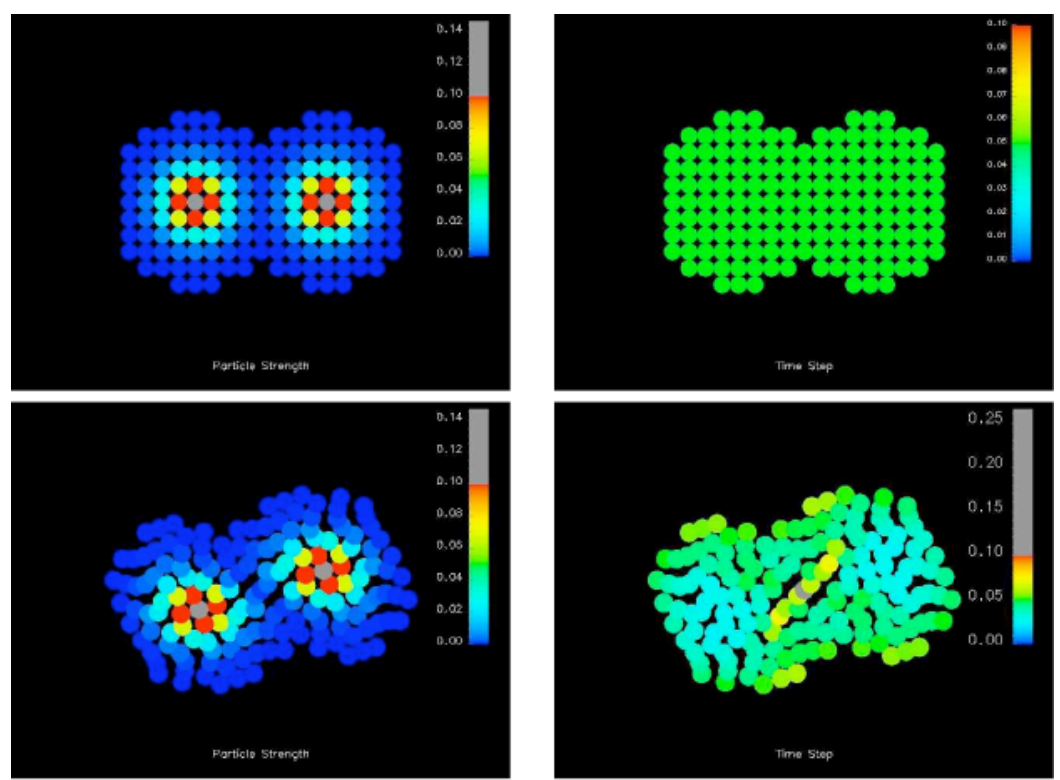

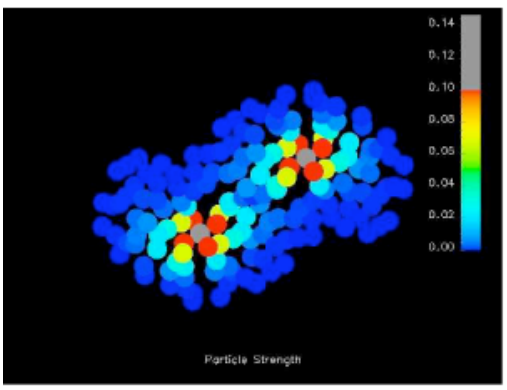

Particle strength

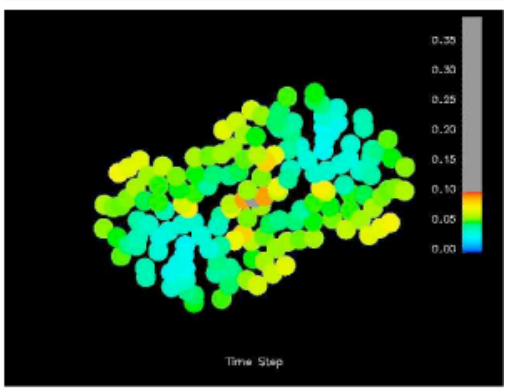

T imestep

Figure 2: Evolving pair of Gaussian vortices on left and corresponding timestep distribution on right. 


\section{NASA Ames Research Center}

As part of a DOE-sponsored study, the aerodynamic drag of $1 / 87^{\text {th }}$-scale coal cars was measured in a wind tunnel. The goal of the experiment was to measure the difference in drag between full and empty cars so as to determine if drag mitigation efforts are warranted.

The measurements were made in the NASA-Ames $15 \times 15$ Inch Low-Speed Wind Tunnel. This is an open-circuit, suction-type tunnel with at square test section measuring 60 inches in length. Five coal cars were mounted on scale train track (Fig 1) with the middle car connected to the upwind car by a 2-lb load cell (Fig 2) and disconnected from the downwind car. All cars except the middle car were glued to the track to prevent motion along the track. This configuration was tested at a freestream velocity of 65 $\mathrm{m} / \mathrm{s}(145 \mathrm{mph})$ with and without simulated coal. The tunnel speed was chosen to maximize the measured drag and minimize measurement uncertainty. The five-car combination was tested at yaw angles of zero and $10 \mathrm{deg}$ to determine the effects of crosswind. The blockage of the coal cars at zero yaw was $0.9 \%$.

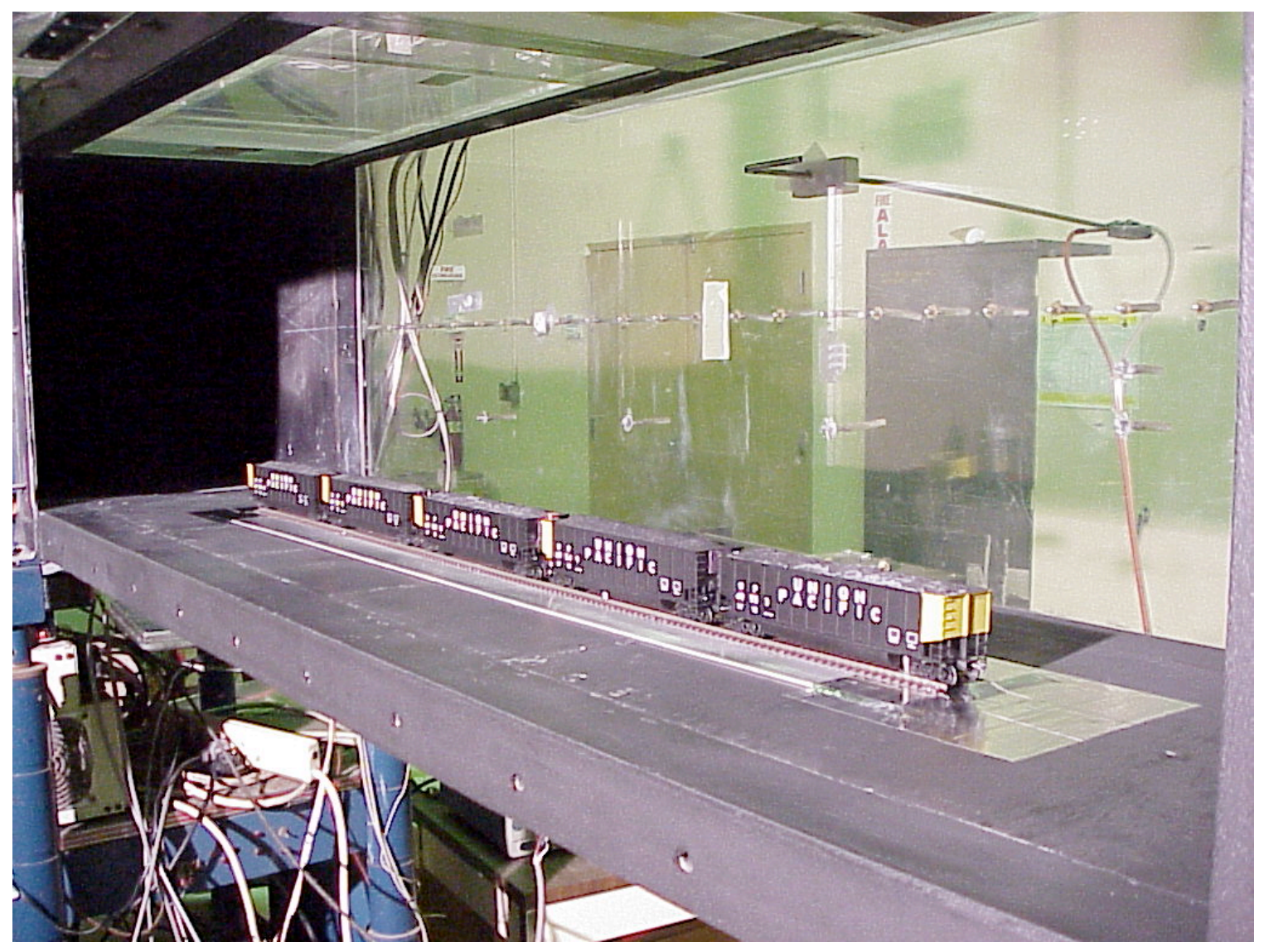

Fig 1 Five coal cars mounted in wind-tunnel test section. Pitot-static probe used for tunnel speed measurement is visible above first car near the top of the photo. 


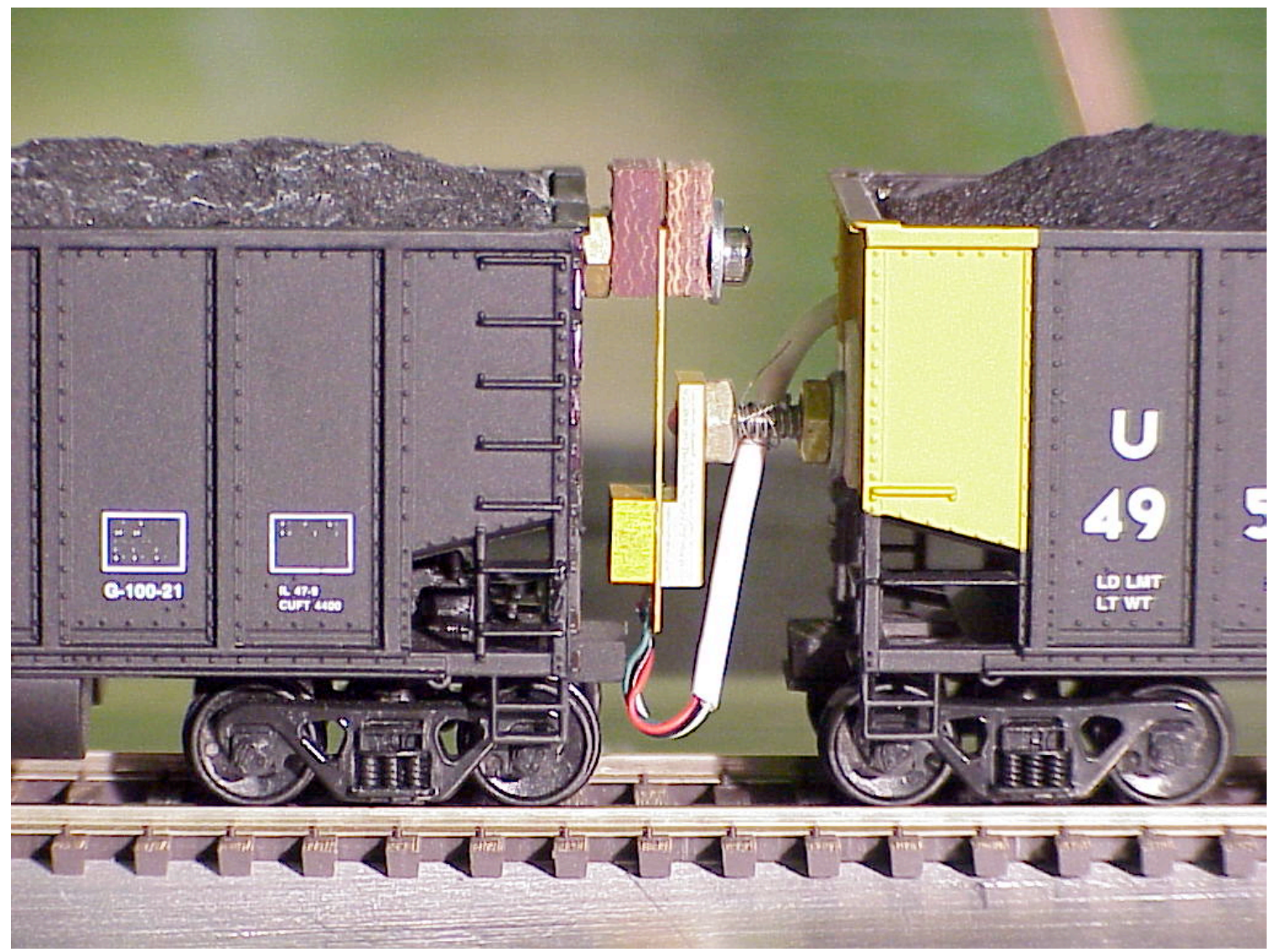

Fig 2 Load cell connecting metric car (at left) to upwind car (at right). The load cell is the thin vertical strip at the center of the photo. Instrumentation wiring enters upwind car in the white cable. Simulated coal is visible in both cars.

The small- and full-scale Reynolds numbers of the coal cars (assuming full-scale velocity of $60 \mathrm{mph}$ ) are 0.16 and 5.8 million, respectively. Due to the nature of bluff-body flow fields, this difference in Reynolds number is not expected to significantly affect the experimental results. The drag coefficient for each configuration (Table 1) was calculated based on the square root of the zero-yaw frontal area. The uncertainty based on measurement resolution and repeatability was $1.2-2.5 \%$ depending on the magnitude of the drag measurement. As indicated below, the drag on the full coal car was significantly less than that of the empty car (32\%). This difference was even greater $(42 \%)$ for the 10 -deg yaw condition in which the drag was significantly increased relative to the zero-yaw case. These results suggest that significant fuel savings could be obtained by reducing the drag of the empty coal cars.

\begin{tabular}{|l|l|l|l|}
\hline Yaw, deg & Cd empty & Cd full & \%diff \\
\hline 0 & 0.315 & 0.216 & 32 \\
\hline 10 & 0.519 & 0.300 & 42 \\
\hline
\end{tabular}

Table 1 Drag coefficients for full and empty coal cars at 0 and 10 deg yaw. 


\section{University of Southern California}

\section{Splash \& Spray}

The apparatus for studying the formation of droplets from rolling tires has been designed and is presently being constructed in the USC machine shop. It consists of two rolling wheels mounted by pendulum arms on a sturdy, vertical plate (Figure 1). The wheels are pressed together to form the rolling tire patch. The plane of symmetry between the two rolling wheels becomes the ground plane. Water is introduced upstream from the tire patch, and the water droplet sheet issuing just downstream from the patch is observed with a two-tube Yag laser (5 nano-second pulse time), and digital cameras connected to an ultra-fast computer bus.

The tire size chosen, P145/80R12, is the smallest automobile-sized tire made. The tire diameter is approximately 21 inches. Two buffed tires (no tread) have been obtained from Michelin in Greenville, South Carolina. Michelin has promised to send additional tires with simple tread patterns of our choice. We plan to assemble the apparatus this summer.

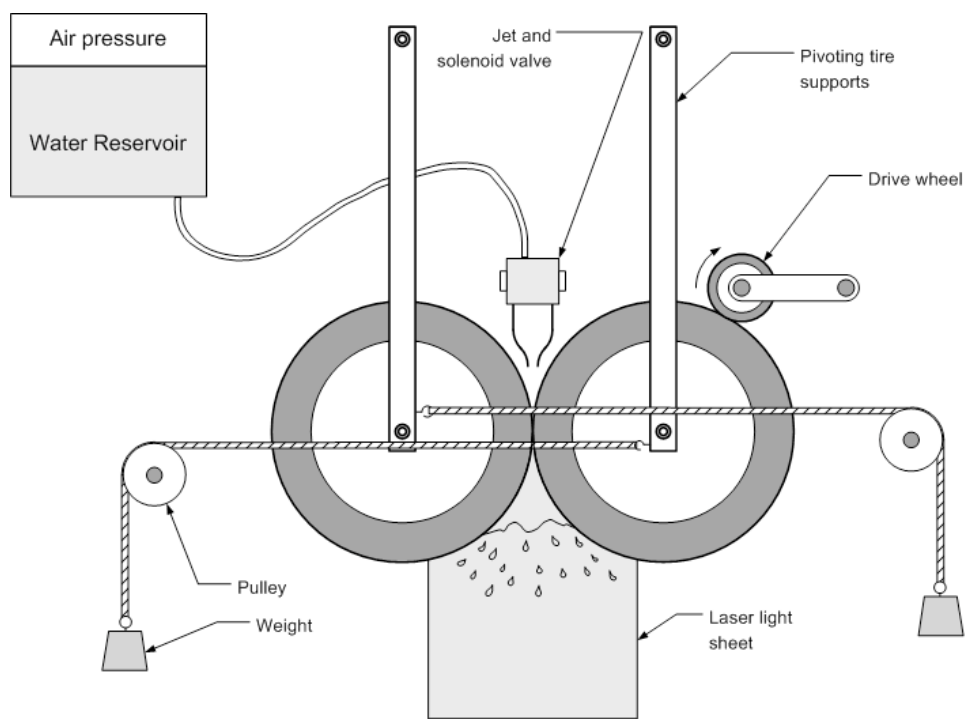

Figure 1. Schematic of dual tire apparatus for splash and spray experiments. The laser pulse duration is of the order of 5 nanoseconds and the time between pulse pairs is adjustable. Two separate images are recorded by a specially designed and buffered digital camera. Droplet sizes and velocities can be determined from these image pairs

\section{Field Tests of Base-Flap Add-ons}

The field tests to measure the drag savings produced by adding inclined flaps along the perimeter of the trailer base is tentatively scheduled for May. (One present difficulty is that our funding has not yet been received.) You recall that, on the basis of wind tunnel experiments in the 12 foot pressurized windtunnel at NASA Ames, we have identified base flaps as the most promising trailer base addition. 
The base flaps are designed and installed by Maka Innovations Technologique, Inc. Wabash trailer has loaned Maka a new trailer. The flaps will be installed at Maka (in Ottawa), and the trailer will be transported to PATH, Berkeley. The tests will be conducted at Crows Landing (in the San Joaquin valley) by PATH personnel under the supervision of USC. The tests will consist of numerous passes on the unused naval air station runway at Crows Landing. The angle of the base flaps will be varied from 13 degrees to 22 degrees to find the optimum performance angle. Instantaneous fuel consumption will be recorded for each pass. Both North and South passes over the same stretch of runway are vital to minimize the effects of wind and of runway elevation variation.

A related study was conducted by PATH and USC in December to judge the fuel savings to result from operating two trucks in tandem. These results are shown in Figure 2. The vertical axis is the measured change in fuel consumption, expressed as a percentage of the fuel consumed by the same truck in isolation. The fuel savings are substantial. 

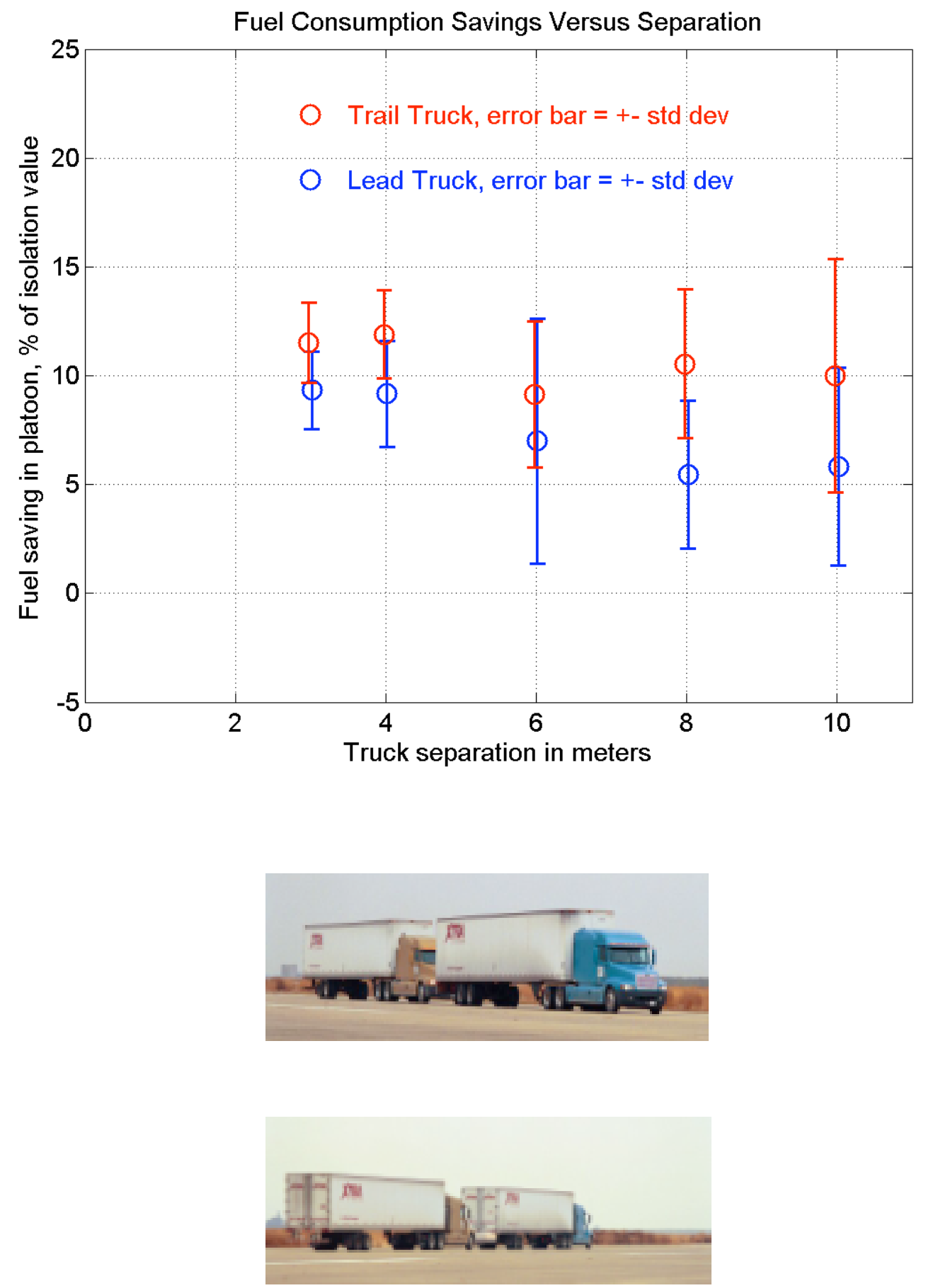

Figure 2. Experiments at Crows Landing in California. 


\section{Argonne National Laboratory}

\section{PACCAR CRADA}

In preparation for simulations of the pending PACCAR/University of Washington wind tunnel experiments, a preliminary series of parametric studies has been initiated to evaluate the need to include the geometry of the wind tunnel in the simulations of these experiments. Using the Commercial Computational Fluid Dynamics (CFD) code Star-CD, four different geometries have been developed:

(1) the exact wind tunnel geometry with the ground plane installed (no slip walls, ceiling and floor),

(2) an extrusion of the cross-section of the test section (no slip walls ceiling and floor),

(3) a rectangular box matching the primary dimensions of the test section (no slip walls, ceiling and floor), and

(4) a rectangular box matching the primary dimensions of the test section (full slip walls and ceiling, no slip floor).

Flow through each geometry will be simulated for mass flow rates corresponding to a velocity of 1.0, $2.5,5.0,7.5,10.0$, and $12.5 \mathrm{~m} / \mathrm{s}$ at the inlet of the exact wind tunnel geometry. Initial efforts in this task have focused upon the simulation of the airflow through the exact wind tunnel geometry, which is shown in Figure 1. Figure 1 also shows the velocity magnitude and turbulent viscosity where the inlet flow has a velocity of $7.5 \mathrm{~m} / \mathrm{s}$. For this case, the average velocity in the test section is approximately $52 \mathrm{~m} / \mathrm{s}$ for a Reynolds number of approximately 2.0 million, and the boundary layer has a thickness of approximately $25 \mathrm{~mm}$. While empty tunnel survey data with the ground plane installed is not available for comparison with predictions, comparisons between predictions from the different cases should be sufficient to determine whether using the rectangular geometry with full slip walls and ceiling rather than the exact wind tunnel geometry in the simulations of the experiments can be expected to significantly hamper predictive capability.

\section{GCM Studies}

Efforts to develop guidelines for the application of commercial CFD software for the prediction of aerodynamic drag of heavy vehicles have shifted in focus from half vehicle geometries to full vehicle geometries. Previous results have shown that, at least for coarsely meshed models (near vehicle cell sizes of 12 and $16 \mathrm{~mm}$ ), simulation of the full vehicle rather than a half vehicle with a symmetric boundary condition applied at the symmetry plane leads to improvements in the prediction of measured drag coefficients. With recent improvements to the front end computational platforms used to generate these computational domains, finer meshes like those used in the half vehicle studies can now be developed for the simulation of the full vehicle. Meshes with near vehicle cell sizes of 6,8 and $10 \mathrm{~mm}$ have been generated and simulations using these meshes will be completed for comparison with wind tunnel data early in the next quarter.

In addition to the efforts with the full vehicle at zero yaw, evaluations of predictive capability for the full vehicle geometry at a yaw angle of 10 degrees are also underway. Initial coarse mesh simulations have used near vehicle cell sizes of 12 and $16 \mathrm{~mm}$, generated using the same semi-automatic localized 
refinement scheme employed in all other studies using the Star-CD CFD software. Using the standard high Reynolds number k- $\square$ model with a logarithmic law of the wall function, a drag coefficient of 0.5098 is predicted in the $16 \mathrm{~mm}$ case, and a drag coefficient of 0.4588 is predicted in the $12 \mathrm{~mm}$ case. More finely meshed computational domains have been generated and will be used in simulations in the coming quarter. Comparisons with experimental data will be made upon the completion of all planned simulations. Calculated streamlines illustrating the behavior of the flow field over the yawed vehicle in the $16 \mathrm{~mm}$ case are shown in Figure 2.
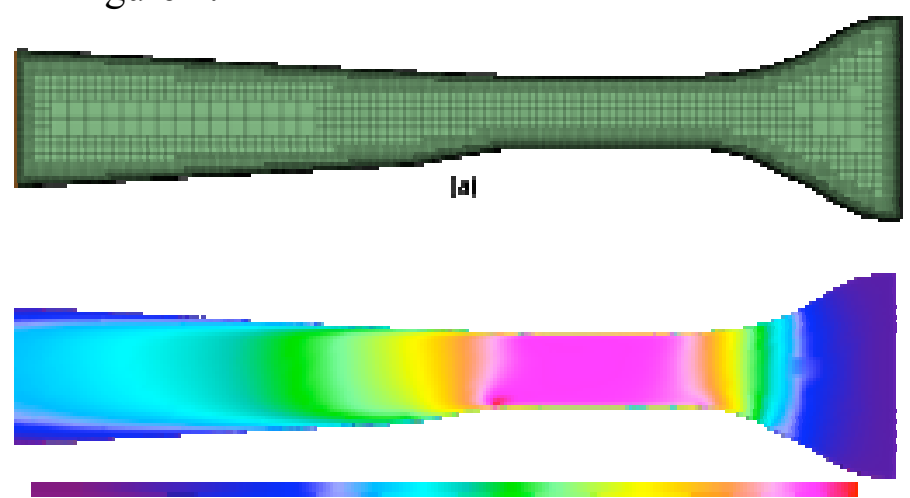

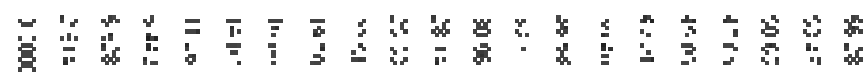

|b|
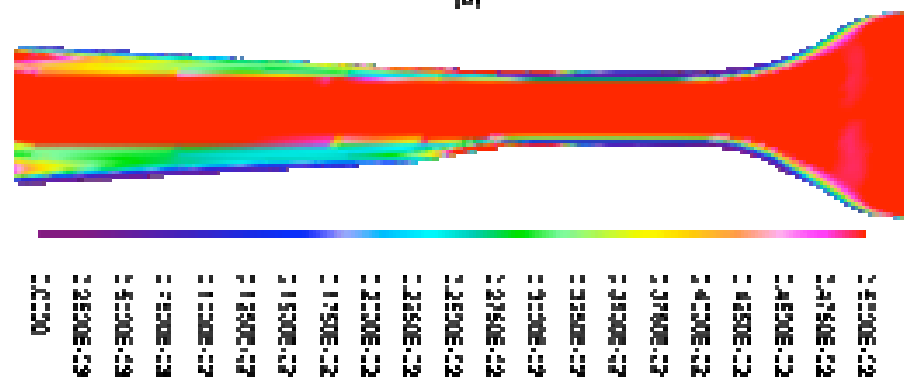

IE!

Figure 1. Simulations of the empty University of Washington wind tunnel have been completed in preparation for the simulation of te PACCAR truck geometry. This figure shows (a) the computational grid at the centerplane, (b) the velocity distribution at the centerplane, and (c) the turbulent viscosity distribution at the centerplane. 


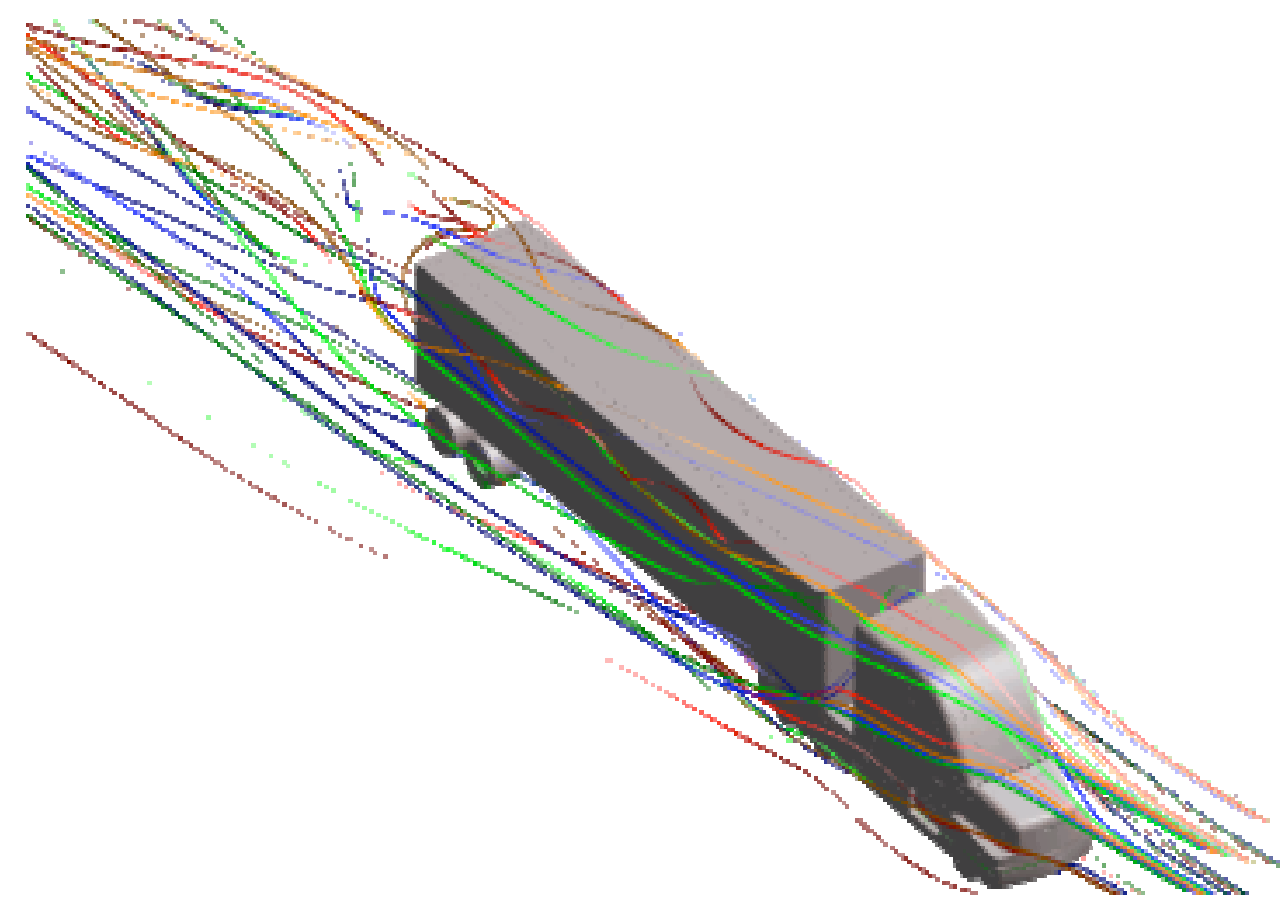

Figure 2. Calculated Streamlines illustrating the predicted flow field over the GCM geometry at a 10 degree yaw angle. 